Article

\title{
A Mind Trying to Right/Write Itself: Metaphors in Madness Narratives
}

\author{
Renana Stanger Elran \\ Independent Researcher, Modiin 7172420, Israel; renana.elran@mail.huji.ac.il
}

Received: 20 February 2019; Accepted: 19 June 2019; Published: 25 June 2019

\begin{abstract}
This article explores autobiographical madness narratives written by people with lived experience of psychosis, dated from the mid-19th century until the 1970s. The focus of the exploration is on the metaphors used in these narratives in order to communicate how the writers experienced and understood madness from within. Different metaphors of madness, such as going out of one's mind, madness as an inner beast, another world, or a transformative journey are presented based on several autobiographical books. It is argued that these metaphors often represent madness as the negative picture of what it is to be human, while the narrative writing itself helps to restore a sense of belonging and personhood. The value and function of metaphors in illness and madness narratives is further discussed.
\end{abstract}

Keywords: psychosis; madness; schizophrenia; narrative; autobiography; metaphor; history of

\section{Introduction}

Madness challenges the mainstream way of being a person in the world; going out of one's mind is also going out of the matrix of normative thoughts, emotions, and actions. A person going through a psychotic episode (psychosis being the archetypal representation of madness) is deeply convinced by the subjective experience of reality, though it seems unlikely or even bizarre and differs from what is understood by others to be real. When psychotic experiences are looked upon in retrospect, the story of the self in times of madness can seem to the person themselves as deeply intimate but also as strange and alien, both profound and meaningless at the same time. If a person chooses to write down these experiences, the narrative produced will be part of a genre known as "illness narratives", or more specifically "madness narratives".

The focus of this exploration is on narratives of psychosis, written mostly by people who received the medical diagnosis of schizophrenia (though it should be noted that the criteria for this diagnosis has changed over the years) and were often hospitalized or treated otherwise. I will be using the terms madness, schizophrenia, and psychosis interchangeably, with the following distinctions: the use of the term schizophrenia refers to the psychiatric nosology; the use of the concept psychosis refers to psychological experiences, mostly of delusions and hallucinations; and the use of word madness indicates a more intuitive understanding of the experience, which is also connected to social and cultural imagination. Within these narratives, I focus on the writers' use of metaphors in order to describe their experiences of psychosis. I argue that autobiographical narratives of psychosis change over time in relation to contemporary psychological understanding of psychosis. In addition, I suggest that these narratives share a common ground, since they often challenge society's core ideas regarding what it means to be human, in the sense of normative concepts of self and personhood within a certain social context. 


\section{Madness Narratives}

Arthur Kleinman argued that illness is a multidimensional phenomenon (Kleinman 1988). According to his conceptualization, the subjective experience of being sick is termed "illness"; the professional's biomedical perspective is termed "disease"; and the sociocultural dimension which reflects wider social forces is termed "sickness". These three dimensions give a broader picture of what it means to be sick within a certain social and historical context. Narratives describing the subjective experience of the suffering person are thus called "Illness narratives". The person who writes an illness narrative, which in the case of psychosis is a subjective account of madness, is faced with the challenge of putting into words what often defies language itself. When representing madness in everyday language, the writer relies upon contemporary understanding of madness but may also challenge current ideas and suggest personal insights, and understandings. In fact, madness narratives challenge the ways in which we are used to thinking about ourselves, and about what it means to be a person in the world.

Autobiographical narratives of psychosis tell, in retrospect, the first person lived experience of a psychotic breakdown. These are nonfictional published stories in which diagnosed sufferers portray hospitalization and treatment methods; they provide their own explanatory models for their illness; they wish to inform and educate family members and the wider public about what mental disorder is and what it is not; and they suggest treatment methods that they believe helped them to recover, and inspire hope in other survivors. Most prominently, however, they describe their own lived experiences-how they felt and what they thought when they were caught in the midst of madness. ${ }^{1}$

The madness narratives are important as a bottom-up experience-based source of knowledge, which in recent years is understood to be valuable for the understanding, treatment, recovery, and empowerment of people with lived experience of psychosis. The narratives can become a valuable resource for studying subjective experiences of psychosis, since each narrative represents an active effort to write the individual story of the self in psychosis. Furthermore, when these narratives are viewed chronologically on a continuum, they portray a written history of psychotic experiences, as described from within.

Madness narratives are not a modern phenomenon. They go as far back as the 15th century (Kempe [1436] 2004) and have existed alongside theological, medical, and psychological literature on madness. These narratives have often been marginalized, excommunicated, and considered to be nothing but a popular reading for the lay public (Porter 1993). In fact, they can show what no theory can capture- the elusive nature of mad experiences as described not by those in the center of power, but rather from the margins of the discourse (Foucault [1965] 1988). Thus, madness narratives are not only stories and histories-they challenge normative perceptions of selfhood and are also political speech acts that give voice to voices that society would rather not hear.

One of the most renowned definitions of how Western modern society perceives the Self belongs to the anthropologist Clifford Geertz (Geertz 1975), which describes "the Western conception of person as a bounded, unique, more or less integrated motivational and cognitive universe; a dynamic center of awareness, emotion, judgment, and action organized into a distinctive whole and set contrastively both against other such wholes and against a social and natural background" (p. 48). It is this concept of the Self that stands in the center of Western autobiographical writing, since autobiography as a literary genre is mainly concerned with the experience of the self, and with the story of how a specific self came into being. The classic definition of autobiography is a story in which "a self-reflective person asks 'who am I?' and 'how did I become what I am?'” (Weintraub 1978, p. 1). This genre assumes the continuity of the " $\mathrm{I}$ " over time and place, as well as its wholeness, individuality, and agency in the world.

But what if an autobiography does not aim to describe normal selfhood but rather a severe disturbance in the sense of continuity and unity of the self, going as far as the collapse of subjectivity

1 For an extensive bibliography of madness narratives see (Hornstein 2011). 
and the breakdown of selfhood? Indeed, people who write about lived experiences of psychosis wish to describe a rupture in the fabric of the self, an interruption in their life story. In fact, it is precisely the capability of creating a reflective and coherent narrative of the self as a rational agent in the world, as well as the capacity for symbolization, which are thought to be interrupted in psychosis. So how does one tell a subjective story about the collapse of subjectivity?

\section{The Value of Metaphor}

Metaphors shape human communication by conveying meaning and are part of the ways in which we think, feel, and act (Laktoff and Johnson 1980). They are also intrinsically connected to life narratives. James Olney (Olney 1972) in his book Metaphors of Self: The Meaning of Autobiography argues that the connection between metaphors and autobiography runs deep. He points out that autobiographical writing is essentially the author's attempt to create a metaphor of selfhood:

The self expresses itself by the metaphors it creates and projects, and we know it by those metaphors; [ ... ] We do not see or touch the self, but we do see and touch its metaphors: and thus we "know" the self, activity or agent, represented in the metaphor and the metaphorizing. [ ... ] It is only metaphor that thus mediates between the internal and the external, between your experience and my experience, between the artists and us, between conscious mind and total being, between a past and a present self, between, one might say, ourselves formed and ourselves becoming. (pp. 34-35)

Many writers of madness narratives use metaphors as a way to communicate to others what madness meant to them and how it felt like to be mad. These personal metaphors of madness represent inner and deeply subjective experiences that differ according to the personal perspective. At the same time, the different narratives make use of popular ideas and public imagery of madness as building blocks and are influenced by the changes in psychiatric and psychological understanding regarding psychosis, and the concept of schizophrenia. This reflection of both personal and public concepts renders metaphors of madness as focal points for exploring autobiographical accounts of psychosis.

\section{Exploring Metaphors of Madness in Autobiographical Narratives}

I will present some of the metaphors used in madness narratives from different time periods, beginning in the mid-19th century up to the 1970s. By exploring core metaphors, one can listen to both the text and context of these narratives. Historicizing and contextualizing metaphors of madness allows exploring ways in which inner and outer realities, text and context, are actively negotiated in autobiographical writing. Through the prism of metaphor, it is possible to examine subjective representations of the experience of madness alongside how such experiences were constructed, and how cultural, historical, and theoretical ideas enter into a person's life story and become part of the subject's identity.

In order to show how metaphors in madness narratives change over time, and relate to psychological ideas regarding psychosis, I explore autobiographical narratives written over a wide scope of time- from the mid-19th century up to the late 1970s. This timeframe was chosen because it relates to a few major changes that occurred in the history of the diagnosis of schizophrenia, as well as to changes in psychological theories regarding psychosis. Since the concept itself of schizophrenia is a modern one, dating to the late 19th century, I begin the exploration with a narrative from roughly that time period. The exploration ends in the late 1970s, with a notable decline in the popularity of psychological, and specifically psychoanalytic, understanding, and treatment of psychosis. This exploration could continue and include the rise of the biomedical model of schizophrenia, as well as the changes brought by the consumer movement-but I will leave these for future exploration. I am aware that such a wide scope has its faults. I sketch the changes in both narratives and psychological theory in wide brush strokes, rather than in a more precise way. But I hope that this scope will allow me to roughly tell a history of psychosis, as told from within. 


\subsection{Out of His Mind: A Madman's Plea for Public Change}

I begin my exploration with two narratives of psychosis that are deeply concerned with changing public opinion, as well as improving the treatment of asylum inmates-John Perceval's 1830-1832 narrative (Perceval [1838-1840] 1974), and Clifford Beers's 1908 A Mind that Found Itself (Beers [1908] 1921). Both authors experienced severe psychosis and wrote retrospective accounts of their illness, hospitalization, and recovery. They both also pursued a role of public advocacy on behalf of the mad. Their narratives represent an interesting intermediate position between 19th century narratives that tend to adopt a more religious language for describing madness and beginning of the 20th century narratives that are already occasionally informed by psychological ideas.

Perceval's narrative was originally titled: A Narrative of the Treatment Experienced by a Gentleman, During a State of Mental Derangement; Designed to Explain the Causes and the Nature of Insanity and to Expose the Injudicious Conduct Pursued Towards Many Unfortunate Sufferers Under That Calamity. It reflects an overlap of a traditional religious outlook that locates the causes of madness (and its cure) on a cosmic-theological level, alongside a more rational outlook that views madness as a disorder that happens on the mental plane of the individual—a loss of reason and rationality.

Perceval writes his narrative because he wishes to address the madman's family members and to inform them regarding his needs and sensitivities. He writes:

By detailing and explaining his sufferings, and his complaints, and his difficulties-he hopes to teach the wretched and affectionate relations of a deranged person, what may be his necessities, and how to conduct themselves toward him, so that they may avoid the errors which were unfortunately committed by the author's own family. (Author's preface to the 1840 edition)

Perceval continued to address his readers directly with a plea for both empathy and sympathy towards the afflicted, in an attempt to stir compassion and engage the reader in dialogue with the madman. His book aims to bridge between the world of madness and that of sanity and to remind his readers that the mad are suffering human beings. He explains that his reason for writing the book is:

Because I wish to stir up an intelligent and active sympathy, in behalf of the most wretched, the most oppressed, the only helpless of mankind, by proving with how much needless tyranny they are treated [ ... ] I open my mouth for the dumb; [ ... ] In the name of humanity, then, in the name of modesty, in the name of wisdom, I entreat you to place yourselves in the position of those whose sufferings I describe, before you attempt to discuss what course is to be pursued towards them. Feel for them; try to defend them. Be their friends ... (pp. 3-4)

Perceval did not renounce the religious experiences he had while in the realms of madness. He went on believing that his madness was inflicted by a divine power, and also cured by its grace. From his point to view, madness had both meaning and method, unlike the views held by his doctors and family members, who insisted on perceiving madness as meaningless folly. He claimed that his return to sanity was encouraged by performing thought experiments that helped him to free himself from the illusionary contents of his mind and to understand his delusions and hallucinations as carrying poetic and symbolic meaning.

\subsection{A Mind That Found Itself}

Clifford Beers's book, A Mind that Found Itself, written in the beginning of the 20th century, no longer uses religious language in order to explain madness, in the sense of predominantly understanding madness as something that enters a person from without and possesses him. Rather, the book represents madness as a phenomenon of the mind in terms of loss of reason, rational thought processes, and loss of consciousness, which he attributes to chance or to a depleted physical condition. He writes in the introduction to his book: 
This story is derived from as human a document as ever existed; [ . . ] It is an autobiography, and more: in part it is a biography; for, in telling the story of my life, I must relate the history of another self-a self which was dominant from my twenty-fourth to my twenty-sixth year. During that period I was unlike what I had been, or what I have been since. The biographical part of my autobiography might be called the history of a mental civil war, which I fought single-handed on a battlefield that lay within the compass of my skull. An Army of Unreason, composed of cunning and treacherous thoughts of an unfair foe, attacked my bewildered consciousness with cruel persistency, and would have destroyed me, had not a triumphant Reason finally interposed a superior strategy that saved me from my unnatural self. (p. 1)

It seems that two metaphors of madness compete in Beers's writing and are also apparent in his deliberation regarding the title of the book. Beers considered naming his book "Reason Triumphant", thus emphasizing the metaphor of madness as an inner civil war fought within the person between Reason and Unreason. But eventually he chose the title "A Mind that Found Itself", stressing that madness is a state of deficiency in which a person has literally "gone out of his mind" or "lost his reason". This central metaphor of madness depicts the madman as being outside of themselves, while the process of recovery is described as the re-finding of the lost rational mind, and the achievement of integration. Beers also evoked a sense of madness as otherness by referring to his own autobiographical writing as partly a biography of "another self". This inner division between the healthy and the mad self might echo the late 19th century's fascination with ideas of "double consciousness" and "split personality".

Both Perceval and Beers believed in the healing power of reason and viewed madness as reversible. They argued that even at the height of madness, a reasonable part of a person is preserved and is able to sanely observe the situation and even reinstate reason by means of intellectual efforts, such as thought experiments. Like Perceval, Beers also wrote in order to change public opinions. He pursued his goal of informing the public on mental hygiene by writing: "a book which would arouse sympathy for and interest in that class of unfortunates in whose behalf I felt it my peculiar right and duty to speak" (p. 213). He declared his motive for writing:

A pen rather than a lance has been my weapon of offence and defense; for with its point I have felt sure that I should one day prick the civic conscience into a compassionate activity, and thus bring into a neglected field earnest men and women who should act as champions for those afflicted thousands least able to fight for themselves. (p. 94)

By writing their personal accounts of madness, these authors wished to transgress their private experiences (perhaps to go out of their own minds?) and to reform the public opinion and understanding of madness as well as to influence treatment methods and legislation. These narratives represent an attempt to participate in public discourse regarding madness rather than to embark on an inner journey. Both Perceval and Beers wrote about the loss of reason and its reestablishment, and by the process of writing and publishing reclaimed their reason and integrity in the public eye. As reasonable men, they were once again equal citizens of the human race, with an active sense of agency, and the survivor's mission to help other afflicted people.

Perceval and Beers continued to influence the public sphere and to actively change the reality of mental asylums. Perceval dedicated the rest of his life to advocating change of the lunacy laws, and to improve the treatment of asylum inmates in England. He was one of the founders of the "Alleged Lunatics' Friend Society" in 1845, along with other ex-inmates and family members (Podvoll 1991). Beers's book became a bestseller and was printed in several editions. He continued his public work on behalf of reforming treatment and preventing mental illness in the USA by creating a national movement called the "Connecticut Society for Mental Hygiene" in 1908 (Dane 1980). Both madness narratives became well known messengers of hope and played a prominent role in their authors' mission to change the public sphere. 


\section{3. "The Beast within": The Rise of a Psychological Paradigm}

Autobiographical narratives of madness written at the beginning of the 20th century reflected the rise of a psychological paradigm of the mind, in particular that of Freudian psychoanalysis, which emphasized the role of the unconscious, drives, and intrapsychic conflict. As the narratives moved into the 20th century, there seemed to be a shift in the central metaphors of madness. Moving away from a mind-centered metaphor of "going out of one's mind" and losing reason, another metaphor is brought forth in two narratives. Jane Hillyer's 1926 Reluctantly Told (Hillyer 1926) and John Ogdon's 1947 Kingdom of the Lost (Ogdon 1947) are two narratives of psychosis, recovery, and overcoming, written in retrospect. Both authors were diagnosed with schizophrenia, hospitalized for several years, and treated in an era before the invention of antipsychotic medication. This was a time in which Freud's ideas about the human psyche were becoming known to psychiatric staff as well to the lay public, including these authors.

Jane Hillyer was hospitalized for a period of four years and received the no-hope-for-recovery diagnosis of "Dementia Praecox" (now labeled schizophrenia). After her release from the psychiatric hospital, she went to psychotherapy and wrote about her experiences. Her story reflects an inner journey into the realms of memory in an attempt to put back the pieces and reclaim mental balance and health-it is a story of "a mind desperately trying to right", and also write, "itself" (p. 142).

There is much emphasis in Hillyer's narrative on madness, specifically on the process of becoming and of being mad. She writes about a moment of recognition when she faced her reflection in the mirror and realized that she had gone mad:

I knew definitely that the figure in the mirror was mad. I was mad. I have never learned words with which to describe the sensations accompanying that realization. I seemed dual; struggling against the truth, crying out against fate, pleading, praying; and at the same time, cool and almost surgical in my analysis of the situation.... I was mad. Again I looked at the mirrored figure. It seemed all eyes. I called it by name. "Do you know," I said, [ .. ] "Do you know what it is like to be mad? That thing will get stronger and stronger. Some day it will be you". The figure in the mirror covered its face. (p. 14)

As she begins to describe this critical moment of split consciousness, she realizes that she had "never learned words with which to describe the sensations". It is perhaps this struggle for words that produces a metaphor-she names her madness a "thing" and describes it not as a physical or even a psychological process but as a living, beastly entity that possessed her and eventually overtook her:

A human being had turned beast; its hair was in a mat over its eyes; its face twisted and marred by rage and pain. [... ] Yes, this thing was "me", the thing that had brought me to my feet in the middle of the night months before with its sinister prophecy, had indeed ceased to haunt, and had become incarnate; it had made its spring and landed full and square. (p. 83)

As she elaborated on her experience of madness as a beastly thing that overcame her, she revealed that for her, going mad meant becoming a nonhuman "Other". The feeling of losing a subjective human identity is closely connected in her description to an upheaval of uncontrollable drives: "I was, during my worst periods, a mere expression of the great drives, hunger, fear, sex-the element of self-preservation alone was lacking" (pp. 42-43). For her, madness represented a dominance of feelings over rational thought: "Lying there I came as close, I think, as I ever have to a state of emotion unaccompanied by thought. I simply felt" (p. 71). Hillyer depicted madness as an affective and physical experience beyond language and beyond symbolic expression. Going mad meant loss of contact with human reality, intellect, and language; becoming a nonhuman stranger to one's self and world.

The metaphor of madness as a beast can be seen as a poetic strategy that gives madness a name and a face, thus allowing Hillyer to turn her inner experience into a character in a story, with which she can now converse. But the metaphor is not just a literary strategy nor an aesthetic choice; it is a genuine 
attempt to give words to a strange and unfamiliar experience. Her agonizing feeling that in madness, "a human being had turned beast", was no symbolic metaphor but a concrete reality of misery and degradation. It might well be that in the course of therapy and of autobiographical writing, which seem to share the same logic of returning to forgotten memories, the concrete experience was transformed into a symbolic metaphor. Retrospectively, the menacing inner beast came to symbolize the loss of humanity, coherent identity, and subjectivity. Thus, it functioned in the narrative as a representation of an actual experience of madness, as well as a poetic metaphor.

The text and its metaphors should also be viewed within context, or they might lose some of their meaning and fine nuances. In comparison to Perceval's and Beers's narratives, Hillyer's book stands out and marks a shift, in which madness became connected to childhood memories, past experiences, and inner drives. Her narrative seems to be influenced by ideas that were brought forth by psychoanalysis, specifically the idea that there are primitive and powerful psychological forces that are buried deep within the person and influence the human mind (Freud 1917).

Though Hillyer did not mention Freud in her narrative, she wrote in a time period in which there already was a wide popular understanding of psychology and psychoanalytic ideas. She did occasionally use Freudian concepts such as drives, resistance, the "censor", and the known metaphor of therapy as an archaeological excavation. Her metaphor of madness as a beast does not refer to a possession by a demonic spirit, but rather to her own sexual drives and childhood memories, buried deep inside. Her inner demons are what comes to haunt her many years later and are understood and narrated within a psychological language for madness. Thus, her narrative reflects the subtle ways in which theoretical and cultural ideas pervade into the inner text of illness and subjectivity and become one of the voices in the person's narration of experience.

\subsection{The Mystery of the Unconscious}

While the connections between Hillyer's metaphor and psychoanalytic ideas were quite subtle, John Ogdon's 1947 The Kingdom of the Lost was a narrative clearly told within a psychological framework. Ogdon's narrative is a particularly interesting case for examining the complex and intertwined relations between metaphors of madness and psychological theories, since Ogdon was not only a diagnosed schizophrenic but also a student of academic psychology. His split narrative was structured from a theoretical review of the literature describing the clinical picture of schizophrenia, followed by his subjective account of illness and self-induced recovery. His viewpoint on madness was not integrative but rather double: theoretical and subjective; based on professional knowledge and on experience. From these two viewpoints, the theoretic and the subjective, emerged a metaphor that combined both-the unconscious as an inner beast.

As a scholar, Ogdon was familiar with many psychological theories, amongst others the concept of the unconscious in Freud's writings. But in the description of his own experiences, the unconscious was no longer perceived as a theoretical construct. He acknowledges that his own views of the unconscious were "heretical", that is, in contrast with psychoanalytic dogma. Yet he insisted that his knowledge was valid because it was based on experience. His subjective experience became a source of knowledge, for: "who shall probe the great depths of a man's mind? Perhaps only the man himself" (p. 250). Based on his experience, he wrote: "My own idea of the Unconscious is as of a powerful living Entity" (p. 30), and he described the unconscious as: "A cunning, filthy, and treacherous beast-a Behemoth putting out its tentacles to strangle good things and drag them as prey into its slimy depths" (p. 251).

In his view, the beastly unconscious was not unique to the schizophrenic-it existed in every human being. But he claimed that during a state of madness, the unconscious takes over and the person falls under the control of inner demons. This metaphor of madness as an inner beastly unconscious gone out of control can be understood as an internalization of a psychological concept, which is then reshaped by the filters of experience and eventually expresses subjective knowledge on what madness felt like. 
The metaphor of the beast that appears in both Hillyer's and Ogdon's madness narratives does not describe madness as the mental collapse of reason, but rather as an intrapsychic emotional state, both stormy and instinctual. It brings to mind a picture of a split identity, or a double consciousness (both concepts were popular in late 19th century psychology), where a sane self endures, soberly observing from the margins, while inside a strange and animal-like 'Other' tries to break out, threatening to take over. This metaphor seems to resonate with the popular view of schizophrenia as a "Jekyll and Hyde disorder", which implied a split between a rational persona and a beastly maniac (McNally 2007).

The metaphoric language used by these writers of madness narratives can be viewed, on the one hand, as reflecting the cultural context into which psychological and psychoanalytic ideas about the mind had been introduced. On the other hand, the metaphor described a subjective experience of a split selfhood threatened by the domination of animal instincts, and the collapse of subjectivity. This metaphoric language, describing a split and impulsive mind, echoed an image of the human subject as inwardly fragmented and molded by memory and primitive desires.

\subsection{Madness as a "Land of Light"}

Madness narratives from the 1950s and 1960s reflect yet another change. There seems to be a movement from the representation of schizophrenia as an emotional, stormy, and impulsive condition of the individual to a set of spatial images describing schizophrenia as a foreign country, another world or a parallel reality. These spatial metaphors appeared in two books (amongst others) by Margaret Sechehaye and Renee (Sechehaye 1951a), and Joanne Greenberg (Greenberg 1964).

Renee, in a co-authored book together with her psychoanalyst Margaret Sechehaye, wrote in Autobiography of a Schizophrenic Girl: Reality Lost and Regained that for her, madness was a retreat to a foreign land. In that other place, she felt like an automaton, alien and alienated from the outside world. She described madness not as an inner entity but rather as a place:

For me, madness was definitely not a condition of illness; I did not believe that I was ill. It was rather a country, opposed to Reality, where reigned an implacable light, blinding, leaving no place for shadow; an immense space without boundary, limitless, flat; a mineral, lunar country, cold as the wastes of the North Pole. In this stretching emptiness, all is unchangeable, immobile, congealed, crystallized. Objects are stage trappings, places here and there, geometric cubes without meaning. People turn weirdly about, they make gestures, movements without sense; they are phantoms whirling on an infinite plain, crushed by the pitiless electric light. And I-I am lost in it, isolated, cold stripped, purposeless under the light. A wall of brass separates me from everybody and everything. In the midst of desolation, in indescribable distress, in absolute solitude, I am terrifyingly alone; no one comes to help me. This was it; this was madness [ ... ] Madness was finding oneself permanently in an all embracing Unreality. I called it the "Land of Light" because of the brilliant illumination, dazzling, astral, cold, and the state of extreme tension in which everything was, including myself. (p. 33)

Renee gradually came to share her experiences in the "Land of Light" with her therapist, and they ended up writing a co-authored madness narrative, the first of its kind. Though the book is written in collaboration by patient and therapist, it still maintained some of the power relations embedded in the therapeutic relationship, as Renee's part is titled "The story" while the analyst's part is titled "The interpretation", which gives dynamic meaning to the story. Once again, the reader in presented with a split narrative of madness, on one side the subjective story, and on the other side the theory. The analyst explained psychosis as a primary disturbance in the mother-child dyad, which she aimed to repair by becoming a symbolic mother to her infant-like patient. Sechehaye (Sechehaye 1951) invented a new therapeutic technique- "symbolic realization"-in which she connected with her patient through using objects that symbolized emotions and psychological processes (such as feeding Renee with an apple as 
a symbol for nursing from the breast). The analyst did not attempt to bring her patient back into reality, but rather to venture into the psychotic world and use its symbolic language.

\subsection{Madness as Another World}

The spatial metaphor of madness also appeared in Joanne Greenberg's novel, I Never Promised You a Rose Garden. Published under a pen name, Hannah Green, the book was first presented as a fictional novel that told the story of 16-year-old Deborah Blau, written in the third person. Only after a few years did the author disclose that the book was semi-autobiographical, based on her years as a diagnosed schizophrenic hospitalized in the psychiatric institution Chestnut Lodge under the treatment of the psychoanalyst Dr. Frieda Fromm-Reichmann (Hornstein 2000).

Deborah's psychotic inner universe was described as a mythical world named $Y r$, with its own geography, language, and culture, which existed parallel to outside reality. It was a secret place of sanctuary into which she could retreat and find comfort and refuge from an unbearable reality. But, gradually, this inner world became more menacing and demanding, cutting her off from other people, and eventually from life itself. In fact, she described the schizophrenic person as one who shuts out reality and lives in a self-made world:

In all the hospitals she had heard about there were atomized armies of persons who had severed their claims to membership in all the world's other groups and orders. Some [ ... ] had set up their own kingdoms and never seemed to approach, as Deborah did, the edges of terrestrial reality. (p. 60)

In the slow and arduous process of therapy, Deborah's psychotic world came to be understood not as merely a regression into an isolated inner world but also as a means of coping with interpersonal reality and of creating meaning - "the means to stay alive in a world of anarchy and terror" (p. 59). Schizophrenia was explained as an interpersonal response that emerged within a family history and dynamics, and as such, it could be understood and treated. The therapist, functioning as a bridge between the patient's inner world and external reality, asked her patient to take her along with her into the psychotic world. In this journey, the patient was the one that held the map to this other place, while the therapist held the lamp that helped them both to see better in the dark. Together, patient and therapist, they translated the psychotic symbols and came to understand their emotional meaning.

Both narratives, Renee's co-authored autobiography and Greenberg's semi-autobiographical novel, described schizophrenia as another place or world. In a metaphoric sense, schizophrenia was no longer seen as mainly an entity within the individual, but rather as a world peopled with others. I suggest that the emergence of a spatial metaphor of madness signifies a reflection of a conceptual change in the understanding of schizophrenia, which broadened the borders of this disorder. Schizophrenia, which was mainly viewed as an intrapsychic disorder placed within the individual's psyche, came to be understood as a disorder located in the intersubjective space. This change was influenced in particular by the interpersonal approach of Harry S. Sullivan (Sullivan 1974), as well as by Frieda Fromm-Reichmann and Harold Searles. They viewed psychosis as a psychological response to disturbed intersubjective relationships, specifically troubled family dynamics. Psychosis was no longer placed wholly within the individual's psyche, but rather in the space between people-in relationships. Since psychosis emerged within a severed relationship, one could understand and cope with it within a healing therapeutic relationship that gave meaning to psychological experiences. It is no wonder that both books gave a central place to descriptions of psychotherapy, and its healing power, thus reflecting the central status of the psychoanalytic approach as a theoretical and therapeutic model in those years.

\subsection{Criticizing the Psychoanalytic Paradigm}

In the 1960s and 1970s, there seem to be two opposite ways of understanding and representing schizophrenia. The first had to do with the strengthening of the biomedical model of schizophrenia as a mental illness that could be successfully treated with the newly discovered antipsychotic medication; 
the second related to antipsychiatric thinking, emerging as part of the counterculture movement and as a criticism of the biomedical model.

Gregory Stefan (Stefan 1966), in his book In Search of Sanity: The Journal of a Schizophrenic, sought to criticize the psychoanalytic approach to schizophrenia, as an approach that ascribes complicated and erroneous psychological meaning to a disorder that in fact stems from essentially physical causes. He attempted to remove the burden of psychological imagery from schizophrenia and to describe it as a strictly physical disease like any other. In his book, he strongly criticized the blind belief in psychoanalytic theory as a theory that explains away everything but leaves the patients helplessly dependent and lacking a real cure:

Before I was hospitalized I had read numerous psychiatric theories about the cause of neuroses and psychoses. The primary cause is lack of love in childhood, said one analyst. No, said another analyst, it's caused by a weak ego. You're wrong, said a third, it's an impairment of the Id. You're all wrong and you're all right, said still another. It's an impairment of all three psychic levels. The collective subconscious of the race had something to do with it, said another. It is conflict between love and hate, intoned still another. Conflict between husband and wife. Conflict between father and child. Conflict between mother and child. Conflict between subconscious and conscious. Conflict between homosexual and heterosexual drives. Conflict between the individual and society. (pp. 156-57)

Though his doctors insisted that his disorder should be explained by psychological means, Stefan held on to his views that schizophrenia was a physical disease caused by biochemical disturbances and sought treatment by medication and nutritional changes. The biomedical model of schizophrenia has since prevailed and become the dominant paradigm for understanding and treating schizophrenia, while psychoanalytic approaches to the understanding of psychotic states gradually declined.

\subsection{Madness as a Journey of Death and Rebirth}

Stefan's demand to view schizophrenia as a physical disease and to treat it as such reflected a paradigmatic change that occurred in psychiatry with the strengthening of the biomedical model, which was accelerated by the discovery and use of antipsychotic medication in the 1950s. However, several circles in the sixties and seventies associated with antipsychiatric thinking and counterculture sought to undermine the validity of the medical model and to point out that even the term 'mental illness' was naught but a metaphor (Szasz 1960).

The co-authored book by Mary Barnes and Dr. Joseph Berke (Barnes and Berke 1971), Two Accounts of a Journey through Madness, was written in the light of R.D. Laing's antipsychiatric approach (Laing 1960). The two authors—a patient and a psychiatrist—opposed the metaphor of schizophrenia as a mental illness and proposed an alternative metaphoric language to describe the experience of madness. They presented psychosis as a potentially healing journey of death and rebirth which enables the person to search for and become an authentic and creative self. In their understanding, psychosis was not merely an expression of intrapsychic conflicts but mainly linked to problematic family dynamics which identified one family member as a scapegoat (the identified patient-IP) so that the others may live in relative sanity. But schizophrenia was not only perceived as part of a disturbed family dynamic. On a wider scale, schizophrenia was seen as an individual's sane response to an insane world, thus strongly connected to the social and cultural context.

In Mary's family, both she and her brother were diagnosed as schizophrenics. While she joined R.D. Laing's radical therapeutic community in Kingsley Hall, her brother was continuously hospitalized and lived a marginal and marginalized life as a mental patient:

He was caught, stuck in his anger. [... ] The emotional life of the family was killing him, breaking his heart. [ ... ] The rest of the family were considered sane. He was mad. We were all a seething mass of wrath, covered by a film of pretence, a spider's web in which we were 
all caught. The tangle of the emotions of my family was so intense that automatically one member struggling free must be killed, annihilated, rather than the grip loosened. Such was the fear of truth. (p. 17)

While living in Kingsley Hall, Mary Barnes went through a personal journey into the depths of her madness, emerging as an artist and a uniquely creative human being. Barnes and Berke, in the spirit of R.D. Laing's antipsychiatric theory, described the inner journey of psychosis as a psychic escape from family entanglement. If this journey was allowed to take place fully and was properly guided, it could result in a transformation into a free and true Self. Barnes's ideas resembled Laing's theory to such an extent that it begs the question whether she in fact went through an authentic and personal journey or was acting out her therapist's concepts regarding psychosis. Dr. Berke referred to Mary's deep identification with the theory:

It has a lot to do with Mary's embodiment of the thesis that psychosis is potentially enriching experience if it is allowed to proceed full cycle, through disintegration and reintegration, or death and rebirth, as Ronnie [Laing] was fond of calling it. Mary had elected herself to the position of head guinea pig, although the nature of the experiment had been determined by her. That Mary had her 'trip' all worked out years before she had ever heard of Laing or Berke or the rest of us tends to mitigate the criticism that she was simply acting out our fantasies for us. (p. 221)

In accordance with their understanding of madness as deeply connected to relationships between people, and the a-hierarchic life in the Kingsley Hall community, Barnes and Berke attempted to co-author their narratives in the same spirit-not as an account of a therapist and a patient but as two people sharing their experience of madness from two viewpoints. They wished to present an alternative view that respected the subjective experience of madness and enabled the person to be an active agent in the construction of both life and life story.

The end of the 1970s was of course not the end of narratives of psychosis. On the contrary, the publication of such narratives seemed only to keep growing. Narratives from the 1980s and on reflected the dominance of a biomedical approach to schizophrenia as a physical, and perhaps genetic, disease, which could be treated by antipsychotic medication. For some writers, the biomedical model was perceived as a relief from shame and guilt, while for others, it increased stigmatization. The following years also reflected the rise of the consumer/survivor/ex-patient movement that wished to reclaim madness and to allow for a variety of perspectives, including understanding of psychosis as a meaningful spiritual crisis. Throughout these changes, the madness narratives remained a source of subjective knowledge that both reflects current opinions, as well as brings on change.

\section{Metaphors of Illness, Illness as Metaphor}

The madness narratives that were explored make use of different metaphors-madness as loss of reason; an inner beast; another world; a physical illness; a transformative journey of death and rebirth. Indeed, metaphors change. They change from person to person, since they describe a unique human experience and a story of a life. They also change in accordance with changes in cultural imagination, reflecting how madness was perceived in a certain social and historical context.

The idea of paying attention to metaphors of illness is not in itself a new one. A well-known reading into metaphors of tuberculosis, cancer, and AIDS can be found in Susan Sontag's classic work Illness as Metaphor (Sontag [1978] 1990). While suffering herself from cancer, Sontag explored the cultural imagination and the metaphoric worlds that were employed in portraying these fatal diseases. She argued that metaphors of illness reflect deep human fears and have sometimes stigmatized the patients even more than the disease itself, thereby increasing rejection, suffering, and alienation from society. Sontag's aim in revealing these metaphors was clearly to de-mythicize these diseases so that they may be seen for what they are-physical illnesses rather than metaphors or punishments for sins that warrant moral judgment. 
Sontag's argument regarding physical illness was carried over into the field of mental illness and applied to the case of schizophrenia (Finzen and Hoffman-Richter 1999). Schizophrenia seems to fit well into the pattern set by Sontag as it too stirs public imagination; it is not sufficiently explained nor cured; and it encompasses deep fears regarding the disintegration of selfhood, loss of contact with reality, and loss of reason. Therefore, it is not surprising that the imagery of schizophrenia in the public eye is negative and that "the metaphor forwards images of acting out, violence, of incomprehensible bizarre or contradictory behavior and thinking" (p. 15), thus increasing fear and rejection towards people suffering from this disorder.

The abovementioned approach towards metaphors of physical and mental illnesses aims eventually to rid us of these metaphors, which are seen as promoting ignorance and fear. But, paradoxically, this approach also highlights the inevitability of metaphors. It seems that in the face of chronic and severe illness - especially when illness is invisible to the naked eye-we, as human beings, use our imagination and our need for order and meaning making. In an attempt to find reasons and causes for suffering, we come to give illness a face and a name. But metaphors of illness and of madness are not only created by the onlookers from the outside, thus reflecting fear, alienation, and social stigma. They are also created by people that experience illness and madness from within. It is of course possible to see these subjective metaphors as internalization of cultural and historical constructions and as forms of self-stigmatization. But applying such an understanding holds the risk of ignoring the subtle ways in which people act as active agents in their own lives and transform public concepts into private knowledge (Obeyesekere 1982).

An understanding of the necessity and the value of metaphors for communicating the story of a life, and specifically the stories of human suffering and ill health, can make way for a different approach towards metaphors of madness. Instead of treating metaphors of madness as necessarily negative and attempting to dissolve them, one can try to listen to them and to learn more about the textual and contextual dimensions of madness and of madness narratives. The metaphors can then become a valuable research tool for different disciplines and also function as an intermediate space for a meaningful dialogue between viewpoints.

The function of metaphor is first, and most importantly, a poetic instrument for transferring meaning about one semantic field by means of another (Leary 1990). Many writers of madness narratives use metaphors in an attempt to retrospectively represent their experiences and communicate them to their readers. They share the fundamental feeling that there are no ordinary words for communicating their experience of madness and are therefore in need of other poetic means in order to capture the experience in words.

But metaphors of madness are not merely poetic means to the end of representing inner experiences. They can also be perceived as markers of cultural and historical change. The metaphors are constituted of building blocks given to the individual by the surrounding environment and are thus culturally and historically bound constructs. By examining metaphors of madness not only textually but also contextually and chronologically, it becomes more visible how madness was perceived, imagined, and poetically represented by people suffering from it, and how these representations of experience have transformed in light of the changing zeitgeist.

Metaphors of madness can also be of interest from a psychoanalytic point of view, since they reflect the dynamics of psychosis. According to Hanna Segal (Segal 1957), what occurs in psychosis is a collapse of symbolic thinking - the gap between the symbol and the symbolized vanishes and thinking becomes either concrete or oversymbolic. Thus, when a person tells about a psychotic experience in which they were overtaken by a monstrous being - that is no metaphor but a description of an actual experience of possession. The same imagery can be used by a writer while retrospectively narrating psychotic experiences, but this time, the image of the "beast within" is used in order to communicate how madness felt like. It is used metaphorically in order to represent loss of control and of the sense of personhood. 
The telling and retelling of the retrospective madness narrative can be seen as a personal attempt to heal, by transforming the concrete experiences of psychosis into symbolic language, and in the process gain new insight and understanding. The process of transforming a chaotic experience into a more coherent narrative enables the story to be communicated to others who have not experienced madness themselves, as well as to make sense of the experience for one's own sake. Thus, the narratives aid the suffering person in re-creating inner links between thoughts, emotions, and actions, as well as forming connections of empathy and sympathy with the readers. These interpsychic and intrapsychic connections stand at the core of feeling human and perceiving one's self as a part of humanity.

\section{Conclusions: Simply Human}

Metaphors of madness do indeed change over time, but they also share a common ground. Often the metaphors, and in fact the narratives, present a split: between Reason and Unreason; between man and beast; between outer and inner worlds; between theory and subjective experience; between physical and mental illness; between death and life. It seems that within this split, madness is usually presented as the negative side, and even as the negative picture of what it means to be human. Each time and place holds a different concept of what constitutes a person. In an era that values reason above all, madness is understood as the loss of reason. As a psychological paradigm becomes prominent and the human psyche is understood to be constructed from conscious and unconscious parts, madness is presented as the domination of the more primitive and instinctual parts of the mind. When psychological theories come to understand the healthy human being as intrinsically connected to family and community networks, madness is seen as the severance of human ties, and as a retreat into an inner and isolated world.

While metaphors of madness seem to represent the negative of what it is to be human, the madness narratives suggest a movement in the opposite direction. By giving words to a psychotic experience, chaos and turmoil can be transformed into a more coherent narrative. Feelings of alienation and isolation, when communicated to another human being, can build bridges of empathy and sympathy between writer and reader. The shuttering experience of losing one's self can be transformed by means of narrative writing into a renewed sense of being a person in the world. Through these narratives, the lived experience of psychosis, too often silenced and excommunicated, can find a new voice, and come to be listened to as an extreme experience, but yet as still simply human.

Funding: This research received no external funding.

Conflicts of Interest: The author declares no conflict of interest.

\section{References}

Barnes, Mary, and Joseph Berke. 1971. Two Accounts of a Journey through Madness. New York: Harcourt Brace Jovanovich.

Beers, Clifford Whittingham. 1921. A Mind That Found Itself, 5th ed. New York: Longmans, Green \& Co. First published 1908.

Dane, Norman. 1980. Clifford W. Beers, Advocate for the Insane. Pittsburgh: University of Pittsburgh Press.

Finzen, Asmus, and Ulrike Hoffman-Richter. 1999. Mental Illness as Metaphor. In The Image of Madness. The Public Facing Mental Illness and Psychiatric Treatment. Basel: Karger, pp. 13-19.

Foucault, Michel. 1988. Madness and Civilization: A History of Insanity in the Age of Reason. New York: Vintage Books. First published 1965.

Freud, Sigmund. 1917. Difficulties in the Path of Psycho-Analysis. In Standard Edition. London: Hogarth Press, vol. 17.

Geertz, Clifford. 1975. On the Nature of Anthropological Understanding. American Scientist 63: 47-53.

Greenberg, Joanne. 1964. I Never Promised You a Rose Garden. London: Pan Books Ltd.

Hillyer, Jane. 1926. Reluctantly Told. New York: The Macmillian Company.

Hornstein, Gail A. 2000. To Redeem One Person is to Redeem the World: The Life of Frieda Fromm-Reichmann. New York:

The Free Press. 
Hornstein, Gail A. 2011. Bibliography of First-Person Narratives of Madness in English, 5th ed. Available online: http:// www.gailhornstein.com/files/Bibliography_of_First_Person_Narratives_of_Madness_5th_edition.pdf (accessed on 23 June 2019).

Kempe, Margery. 2004. The Book of Margery Kempe. Edited by Barry Windeatt. Cambridge: D. S. Brewer. First published 1436.

Kleinman, Arthur. 1988. The Illness Narratives: Suffering, Healing and the Human Condition. New York: Basic Books.

Laing, Robert D. 1960. The Divided Self: An Existential Study in Sanity and Madness. London: Tavistock Publications.

Laktoff, George, and Mark Johnson. 1980. Metaphors We Live By. Chicago: University of Chicago Press.

Leary, David. 1990. Metaphors in the History of Psychology. Cambridge: Cambridge University Press.

McNally, Kieran. 2007. Schizophrenia as Split Personality/ Jekyll and Hyde: The Origins of the Informal Usage in the English Language. Journal of the History of the Behavioral Sciences 43: 69-79. [CrossRef] [PubMed]

Obeyesekere, Gananath. 1982. The Work of Culture: Symbolic Transformation in Psychoanalysis and Anthropology. Chicago and London: University of Chicago Press.

Ogdon, John Andrew Howard. 1947. The Kingdom of the Lost. London: The Body Head.

Olney, James. 1972. Metaphors of Self: The Meaning of Autobiography. Princeton: Princeton University Press.

Perceval, John. 1974. Perceval's Narrative: A Patient's Account of His Psychosis, 1830-1832. Edited by Gregory Bateson. New York: William Morrow \& Company. First published 1838-1840.

Podvoll, Edward M. 1991. Perceval's Courage. In The Seduction of Madness. London: Century, pp. 1-68.

Porter, Roy. 1993. Hearing the Mad: Communication and Excommunication. In Proceedings of the First European Congress on the History of Psychiatry and Mental Health Care. Edited by Leonie de Goei and Joost Vijselaar. Rotterdam: Erasmus Publishing.

Sechehaye, Margaret. 1951. Symbolic Realization: A New Method of Psychotherapy Applied to a Case of Schizophrenia. New York: International Universities Press.

Sechehaye, Margarete. 1951a. Autobiography of a Schizophrenic Girl: Reality Lost and Regained. Translated by Grace Rubin-Rabson. New York: Grune \& Stratton.

Segal, Hannah. 1957. Notes on Symbol Formation. International Journal of Psychoanalysis 38: 391-97. [PubMed]

Sontag, Susan. 1990. Illness as Metaphor and AIDS and its Metaphors. New York: Anchor Books. First published 1978.

Stefan, Gregory. 1966. In Search of Sanity: The Journal of a Schizophrenic. New York: University Books.

Sullivan, Harry Stack. 1974. Schizophrenia as a Human Process. New York: Norton \& Company.

Szasz, Thomas. 1960. The Myth of Mental Illness. American Psychologist 15: 113-18. [CrossRef]

Weintraub, Karl Joachim. 1978. The Value of the Individual: Self and Circumstance in Autobiography. Chicago: University of Chicago Press. 